\title{
PREVALENCE OF THIELERIASIS AND ITS VECTOR IN CATTLE IN NEW-VALLEY GOVERNORATE, EGYPT
}

\author{
By \\ SARA M. SAYED ${ }^{1}$, SOTOHY A. SOTOHY ${ }^{2}$, MOSTAFA A. SALEH ${ }^{3}$, \\ AHMED G. ABDELAZEEM ${ }^{4}$ AND AHMED K. DYAB ${ }^{5^{*}}$
}

Animal Health Research Institute of New Valley, Egypt ${ }^{1,3}$, Department of Veterinary Hygiene, Faculty of Veterinary Medicine, New Valley University, Egypt ${ }^{2}$, Department of Parasitology, Faculty of Veterinary Medicine, Aswan University, Egypt ${ }^{4}$ and Department of parasitology Faculty of Medicine, Assiut University ${ }^{5}$

( ${ }^{\star}$ Correspondence: ahmedsaf2001@yahoo.com)

\section{Abstract}

The present study was conducted for one year period extended from April 2018 to March 2019 which aimed to evaluate some epidemiological, clinical and diagnostic state of tropical theileriasis and tick infestation on cattle in New-Valley Governorate. For this purpose a total of 414 cattle of different ages, sexes and from different localities were examined for Theileria annulata infection and tick infestation. The result of tick infestation on cattle showed that the prevalence was 116 out of 414 examined samples (28\%) were positive for tick infestation. Only one tick species, Hyalomma anatolicum was identified during the present study. Also, the results revealed that 160/414 (38.65\%) of examined cattle were positive for Theileria annulata infection.

Keywords: Egypt, Cattle, Theileria annulata, Ticks, Hyalomma anatolicum.

\section{Introduction}

Theileriasis is economically an important disease in several countries worldwide. Losses in terms of vaccination and treatment cost, reduction in live weight of sub-clinical cases, mortality in animals, increase in inter calving interval, reduction in milk off take, delay in the age of maturity of affected female animals were reported (Gharbi et al, 2006). In Egypt bovine theileriasis is a tickborne disease caused by $T$. annulata and led to severe losses in production and reproduction of cattle (Al-Hosary, 2009). Tick infestation in cattle is one of the major constraints to the livestock industry in developing countries which adversely affects economic performance, mainly by transmission of serious pathogens of animals (Das et al, 2005). Tropical theileriasis caused by the hemoprotozoan parasite Theileria annulata, is exclusively transmitted by ticks of the genus Hyalomma Uilenberg (1981). Its infestation cause losses in livestock production exceed $\$ 2.26$ billion annually Byford et al. (1992). Optimal relative humidity and temperature requirements for growth and reproduction of ticks are $85 \%$ and $26-37^{\circ} \mathrm{C}$ and respectively (Aktas et al, 2004). The patho- gens transmission by ticks depends on a variety of factors including duration of feeding time, pathogen titer, and extent of tissue (e.g., gut, salivary glands) infection at the time of blood feeding. Some pathogens require a period of replication and/or expansion (in response to a blood meal) prior to transmission from a tick. Also, the prevalence of tick infestation in livestock is much higher in developing countries (Roelandt et al, 2010).

This study aimed to assess the prevelance of thieleriasis and its vector among cattle in New Valley Governorate Egypt

\section{Material and Methods}

Study Area: A total of 414 cattle were examined for presence of Theileria spp. infection and tick's infestation in 13 villages of El-Kharga and Baris (New Valley Governorate).

Ticks collection: Before collection of ticks animals were restrain properly and their whole body was thoroughly inspected visually for the presence of tick. Ticks specimens were taken from predilection sites on the hosts as on the ears, dewlap, axillae, udder, groin, shoulders, and belly and around the anus. After detachment of ticks through 
forceps from the animal body, collected ticks were transferred to suitable capped bottles containing $70 \%$ alcohol solution and shifted to the laboratory for permanent slide preparation and identification basing on the characters of the basis-capitulum, pedipalps, presence or absence of festoons, eyes, anal groove, adenal shields, coxa-1, coxa-IV, accessory adenal shields and designs of colors present on scutum (Walker, 2003).

Blood samples collection: Two $\mathrm{ml}$ blood samples were obtained from Jugular vein of 414 cattle of both sexes ( 300 females \& 114 males, aged from 1 to 10 years) into clean dry sterile tubes containing EDTA as an anti-coagulant to prepare blood smears. Smears were air dried, fixed in methanol and stained with Giemsa and microscopically examined for Theileria spp. (Levine, 1985).

\section{Results}

Clinical signs: The present study revealed that infected cattle showed various degrees of the characteristic clinical signs of the tropical theileriosis like fever $\left(>40^{\circ} \mathrm{c}\right)$, enlargement of the superficial lymph nodes (Fig.1), congestion of the visible mucous membranes and corneal opacity (Fig. 2), diarrhea in addition to ticks infestation (Fig. 3).

Prevalence of tick infestation in cattle: From total examined cattle (414), the results showed that $116(28 \%)$ of examined cattle were positive for tick infestation. the highest infestation rate was observed in summer (53.85\%), followed by autumn and spring (33.33\% \& 29.2\%, respectively). However, the lowest rate of infection was observed in winter $(4 \%)$. Cattle at age $>2$ years $(36.3 \%)$ have highest percentage of infestation than cattle at age $\leq 2$ years $(31 \%)$. The higher ticks infestation was present in female (32\%) compared with male (17.54\%). All ticks examined were hard ticks belonging to genus Hyalomma, species Hyalomma anatolicum anatolicum, which were as follows: Grossly, adult male Hyalomma tick showed conscutum dorsal aspect (Figs. 4 \& 5), and engorged female ticks with striations in integument texture (Fig.6)

Microscopic appearance: Mouthparts are anterior and palp articles 2 are longer than articles 1 and 3 (Fig.7). Basis capituli has medium angular lateral margins (Fig. 8). Eyes are always very convex (Fig.9). Legs are slender; usually have pale rings (Fig.10). and anal groove was posterior to anus (Fig. 11). Pulvilli were always present and Ventral plates were present in males only; usually three distinct pairs (Fig. 12). Festoons were in males and in females but unclear in fed females (Fig.13). Coxae 1 have large and equal paired spurs (Fig.14).

Prevalence of Theileria annulata infection in cattle: From total of 414 cattle blood samples, the results showed that $160(38.65 \%)$ were positive for Theileria spp. infection (Fig. 15) and the highest percent of infection rate was observed in summer (58.97\%), followed by autumn (57\%). However, the lowest infection in spring and winter $(41.66 \%$ and $9.8 \%$, respectively), and the prevalence was $(40.91 \%)$ in cattle aged $>2$ years while $(36.08 \%)$ at aged $\leq 2$ years. Also, higher Theileria spp. infection was found in female $(40.66 \%)$ compared to male $(33.33 \%)$. As to parasitemia in blood films was categorized regarding the degree of infected RBCs with Theileria spp. in to (5) divisions as follow; Of 160 infected animals, $90(56.25 \%)$ of cattle were infected with the first degree of infection $(1-2 \%), \quad 28(17.5 \%)$ were present in of infected cattle $(>2-5 \%),(>3-5 \%)$ and $(>$ $10-15 \%)$ recorded in $10(6.25 \%)$ of infected cattle, $34(27.5 \%)$ of infected cattle were the last degree of infection (>15\%).

Table 1: Relation of hard tick infestation with Theileria annulata infection.

\begin{tabular}{|c|c|c|}
\hline Relation of infection with infestation & No. of animals & Percentage \\
\hline Infested - infected & 80 & $69 \%$ \\
\hline Non infested - infected & 80 & $69 \%$ \\
\hline Infested - non infected & 36 & $12 \%$ \\
\hline
\end{tabular}




\section{Discussion}

In the present study, Hyalomma anatolicum infestation was 116 (28\%) among (414) cattle. This agreed with Khan et al. (1993) in Pakistan, who reported $(28.2 \%)$ of tick infestation, but it was higher than that reported by Ramadan et al. (2016) who reported $(6.17 \%)$, and lower than that reported by Hassanain et al. (1997) $80.44 \%$ in Behiera Governorate, Egypt. Ticks distribution varied depending on environmental conditions, host density, host susceptibility, grazing habits and pasture-herd management (Ahmed et al, 2019).

In the present study, the highest tick infestation was in summer $(53.85 \%)$, and the lowest one in winter $(4 \%)$, which agreed with Singh and Rath (2013). No doubt, ticks favor warm summer to infest cattle for their development. As to age, the tick infestation was higher on cattle at age $>2$ years $(69 \%)$. This agreed with Egyptian authors as Abd El-Baky (2001), Abdel-Rady et al. (2008), Abdou et al. (2005), Fadly (2012), Ramadan et al. (2016) and Ahmed (2019).

In the present study, of 414 cattle examined $160(38.65 \%)$ were positive for Theileria annulata. This agreed with Abdou et al. (2005) and Abd-El Rady et al. (2008) who revealed $(40.3 \%)$ and $(40 \%)$, respectively and higher than $(30.98 \%)$ reported by ElFayoumy et al. (2005). But, El-Metenawy (2000) in Saudi Arabia found (76.5\%). The difference may be attributed to geographical and, climatic conditions, as well as management practices (Gul et al, 2015). The highest prevalence of Theileria infection was recorded in summer $(58.97 \%)$, followed by autumn (57\%), then spring (41.66\%) and the lowest rate was in winter $(9.8 \%)$.

In the present study, the tick infestation, the cattle were categorized into 3 groups, $1^{\text {st }}$ group in which were $80(69 \%), 2^{\text {nd }}$ group in which non infested-infected cattle were also $80(69 \%)$, and $3^{\text {rd }}$ group in which infested - non infected cattle were $36(12 \%)$. The reason for presence of non-infested infected cattle is that tick-vector spend most of their life in the soil, and leaf litter in a period of dormancy and only a small fraction of their time seeking out and feeding on hosts. Even in tick species that engage several hosts in their life cycle, more than three-quarters of their lives are spent off-host in the soil or among the leaf litter (Varma, 1993; El Kammah et al. (2001)

\section{Conclusion}

Based on the outcome results the theileriasis was found in New Valley Governorate in high percent among cattle. The presence of theileriasis and its tick vector in other Egyptian governorates affect the meat production and thus the economy. Control of ticks to minimize the disease-transmission is a must by using environmental friend acaricides.

\section{References}

Abd El-Baky, SMM, 2001: Prevalence of external parasites in the south-eastern desert of Egypt. J. Egypt. Soc. Parasitol. 31, 1:223-32.

Abdel-Rady A, Kotb S, AbdEllah MR (2008): Clinical, diagnostic and therapeutic studies on theileriasis (Theileria annulata) in cattle in Upper Egypt. Suez Canal Vet. Med. J. 13, 2:378-95 Abdou, TA, Abou-El-Naga, TR, Mahmoud, MA, 2005: Clinico-pathological Studies on $T h$ eileria Annulata Infection in Siwa Oasis in Egypt. BS. Vet. Med. J, 15, 2:40-6.

Ahmed, S, El-Hakim, OA, Maher, A, Elnaker, Y, 2019: Tropical theileriosis, epidemiology and Molecular diagnosis in cattle in New Valley Province, Egypt. Alex. J. Vet. Sci. 63, 1:31-41

Aktas, M, Dumanli, N, Angin, M, 2004: Cattle infestation by Hyaloma ticks and prevalence of Theileria in Hyalomma species in the East of Turkey. Vet. Parasitol. 119, 1:1-8.

Al-Hosary, AA, Ahmed, J, Nordengrahn, A, Merza, M, 2015: Assessment of the first commercial ELISA Kit for the diagnosis of Theileria annulata. J. Parasitol. Res. 1;1-4.

Al-Hosary, AAT, Ellah, MRA, Ahmed, LSE D, 2018: Evaluation of oxidative stress in sheep infested with ticks and concurrent diagnosis of theileriosis. Asian J. Anim. Vet. Adv. 13:263-8.

Byford, RL, Craig, ME, Crosby, BL, 1992: A review of ectoparasites and their effect on cattle production. J. Anim. Sci. 70, 2:597-602.

Das, G, Ghosh, S, Ray, DD, 2005: Reduction of Theileria annulata infection in ticks fed on calves immunized with purified larval antigens 
of Hyalomma anatolicum anatolicum. Trop. Anim. Hlth. Prod. 37:345-61

El-Fayoumy, MM, Abou-Elnga, TR, Abd ElBaky, SM, Abdout, A, 2005: Prevalence and treatment of camel theileriosis and its vector tick in North Coast of Egypt. Egypt. Vet. Med. Ass. 65:291-2.

El Kammah, KM, Oyoun, LM, El Kady, GA, Shafy, SA, 2001: Investigation of blood parasites in livestock infested with argasid and ixodid ticks, in Egypt. J. Egypt Soc. Parasitol. 31: 365-71.

El-Metenawy, TM, 2000: Prevalence of blood parasites among cattle at the central area of Saudi Arabia. Vet. Parasitol. 87, 2/3:231-6.

Fadly, RS, 2012: Prevalence of blood parasites of some farm animals at Beheira Province. Assiut Vet. Med. J, 58:134-9.

Gharbi, M, Sassi, I, Dorchies, P, Darghouth, P, 2006: Infection of calves with Theileria annulata in Tunisia: Economic analysis and evaluation of the potential benefit of vaccination. Vet. Parasitol. 137: 231-41.

Gul, N, Ayaz, S, Gul, I, Adnan, M, et al, 2015: Tropical theileriosis and east coast fever in cattle: present, past and future perspective. Int. J. Curr. Microbiol. App. Sci. 4, 8:1000-18.

Hassanain, MA, Garhy, ME, Abdel-Ghaffar, FA, et al, 1997: Biological control studies of soft and hard ticks in Egypt. Parasitol. Res. 83, 3:209-13.

Khan, MN, Hayatm, CS, Iqbal, Z, et al, 1993: Prevalence of ticks on livestock in Faisalabad (Pakistan). Pak. Vet. J. 13:182-4.

Levine, ND, 1985: Veterinary Protozoology; Iowa State University Press.

Ramadan, MY, Elakabawy, LM, Elmadawy, RS, et al, 2016: Prevalence of hard tick infesting cattle with a special reference to microscopic and molecular early diagnosis of tick born piroplasms. BVMJ 30, 2:51-60.

Roelandt, S, Heyman, P, Tavernier, P, Roels, S, 2010: Tick-borne encephalitis in Europe: Review of an emerging zoonosis. Vlaams Diergeneeskundig Tijdschrift 79, 1:23-31.

Singh NKJ, Rath SS. (2013): Detection of acaricidal resistance in Hyalomma anatolicum anatolicum. Ind. Vet. J. 90:17-19.

Uilenberg, G, 1981: Theileria species of domestic livestock. In: A.D. Irvin, M.P. Cunningham \& A.D. Young (Eds.), Advances in the Control of Theileriosis Martinus Nijhoff, The Hague.

Varma, MRG, 1993: Ticks and mites (Acari). In: Medical Insects and Arachnids. Springer, Dordrecht.

Walker, AR, 2003: Ticks of domestic animals in Africa: A guide to identification of species. Edinburgh: Bioscience Reports (3-210).

Fig. 1: Enlargement of superficial lymph nodes (Prescapular lymph nodes), X2 (arrow).

Fig. 2: Corneal opacity, X2 (arrow).

Fig. 3: Diarrhea and tick infestation, X2 (arrow).

Fig. 4: Grossly, adult male Hyalomma tick showing conscutum (dorsal aspect).

Fig. 5: Grossly adult male.

Fig. 6: Histogram showing engorged female ticks with striations in integument texture.

Fig. 7: Palp articles 2 longer than articles $1 \& 3$ lens 4/0.1 160/0.17x (arrow).

Fig. 8: Basis capituli with medium angular lateral margins lens 4/0.1 160/0.17x (arrow).

Fig. 9: Eyes very convex lens 4/0.1 160/0.17x (arrow).

Fig. 10: Slender legs with pale rings, lens 4/0.1 160/0.17x (arrow)

Fig. 11: Anal groove posterior to anus. lens 4/0.1 160/0.17x (arrow).

Fig. 12: Ventral plates are present in males only. lens 4/0.1 160/0.17x (arrow).

Fig. 13: Festoons very clear in male Hyalomma tick, lens 4/0.1 160/0.17x (arrow).

Fig. 14: Coxae 1 have large and equal paired spurs, lens 4/0.1 160/0.17x (arrow).

Fig. 15: Thin blood film showing ovoid shape piroplasm of Theileria annulata 1000X (arrow). 

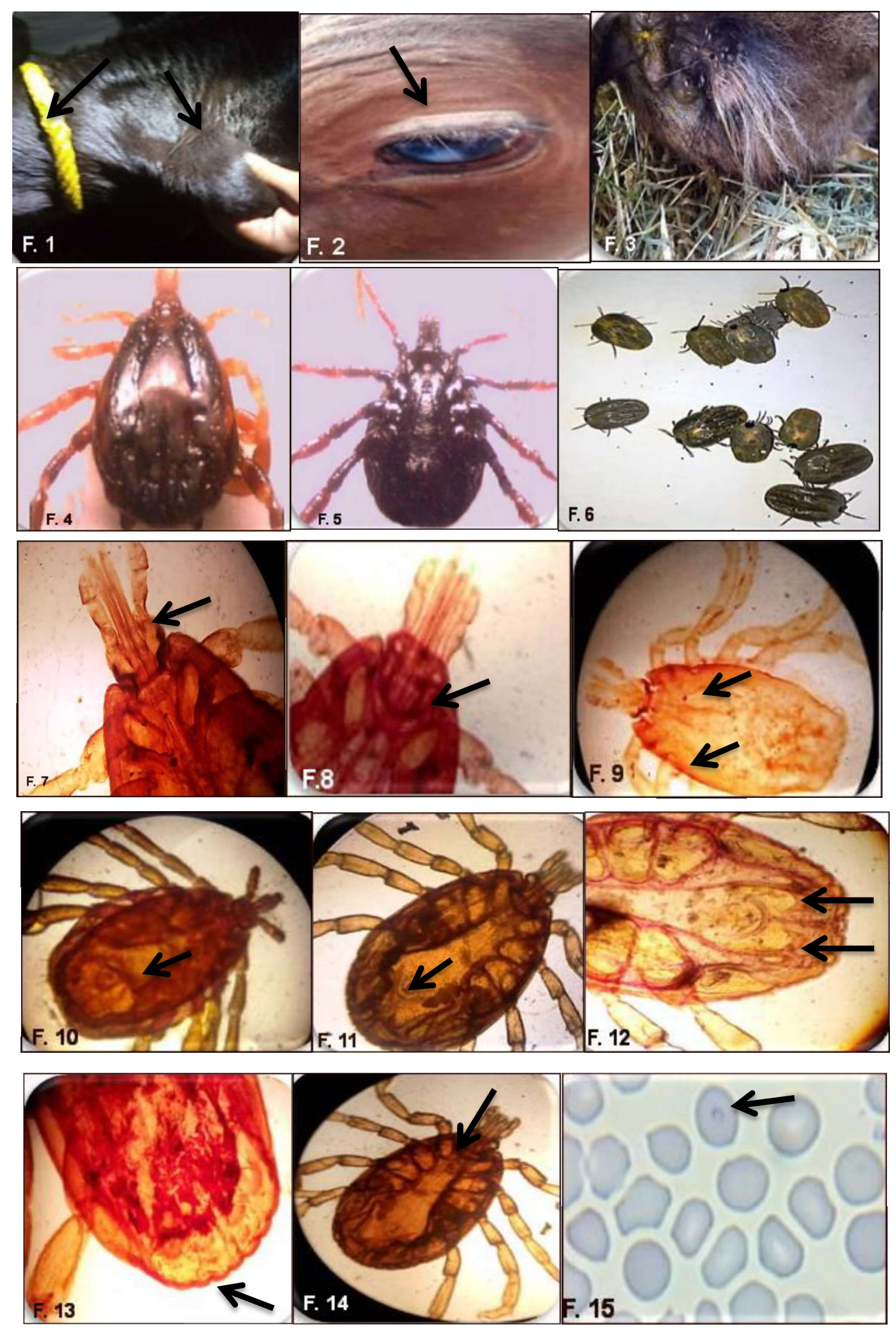